\title{
Intelligent Interactive System for E-Learning
}

Lovemore Gunda ${ }^{1}$ and Malvern Dongeni ${ }^{2}$

\{loveugunda@gmail.com, malverndongeni@gmail. $\left.\mathrm{com}^{2}\right\}$

National University of Science and Technology, Box AC 939, Ascot,

Bulawayo, Zimbabwe $e^{1,2}$

\begin{abstract}
The pipeline of instructional materials and learning infrastructure has not kept pace with the heavy demand on educational facilities. Rising enrolment rates have outpaced the education funding, resulting in shortages of instructional materials, poorly stocked libraries and overuse of existing school facilities. An E-learning software application has been developed to assist students in their laboratory experiments in form of a virtual laboratory simulation package to address the problem. In this paper the design and implementation of an intelligent learning system for both educational and personal use is being. This application integrates the real world into simulation environments enabling learning to be more affordable, accessible and friendly. The system allows a tutor to upload tutorials and experimental procedures and get expected results. The student accesses the application and performs the experiments by following the steps given in form of tutorials. The developed package has been tested and performs simulations on Physics and Chemistry experiments.
\end{abstract}

Keywords: e-learning, virtual lab, education, simulation

\section{Introduction}

Research has shown that students learn by being actively engaged in relevant and authentic activities [1] therefore technology makes this increasingly possible. Learners are also becoming more adept at using social networks such as YouTube and Facebook to send text messages, post videos and images, collaborate and socialize regardless of time or place. Furthermore, students are using software applications to either create or interact with content. Classrooms are becoming "open" through voice, video, and text-based collaboration, and teachers now have a wide range of multimodal resources at their disposal to enhance teaching. Alongside a growing understanding of how the brain works and how learning takes place, integrated technology solutions such as multimedia, games, and animation have played a significant role in improving time to mastery and understanding.

As more people adopt new technologies for learning, they will thrive in the emerging world of the Internet of Everything (IoE), which is the networked connection of people, processers, data, and things and is becoming the basis for the Internet of Learning Things [2]. The whole education sector can be modeled by the following four pillars of education which are people, process, data and devices (Internet of things). The education sector must understand how people connect to the Internet to increase their learning and apply their knowledge as a result. Those learners who thrive will stay current and ahead of the pack. In the words of author Alvin Toffler, [3] there will also be those who know how to "learn, unlearn, and relearn." Finding the right people with and from whom to learn will be crucial. As each individual becomes a "node" on the network, people will need to know how to connect, not just to the work of leading experts, but to peers who have similar passions and interests. In this way, people will share ideas, discuss research or the latest developments in their area of study, and develop increasingly connected communities of practice. Teachers then use class time to discuss problems, work on ideas, and encourage group collaboration.

Process plays an important role in how people, data, and devices work together to deliver value in the connected world of devices. With the correct process, connections become relevant and value is added because the right information is delivered to the right person, at the right time, in an appropriate way. Ensuring that young people have access to learning opportunities that meet their needs will make education more efficient, improve time to mastery, and motivate learners. Such opportunities will also increase student retention and the application of new knowledge, which is vital for future success in both work and society. Much value can be derived from feedback on a student's performance. The model of measurement could be accurate at any moment in time, providing ongoing, targeted, and personalized feedback on what a learner must do to improve his or her understanding and performance. [4]

ACRID 2017, June 20-21, Victoria Falls, Zimbabwe

Copyright (C) 2017

DOI 10.4108/eai.20-6-2017.2275849

472 
As devices connected to the internet evolve, they will also become more intelligent, thereby providing more useful information. Rather than just report raw data, connected things will soon send higher-level information back to machines, computers, and people for further evaluation and quicker decision making. Sharing datasets with others around the world will enhance and extend student's learning experience, authenticating their research through active engagement with other researchers. Not only are learners in contact with researchers, they are working with them to help solve local and global problems.

Devices are physical items that can be connected to both the internet and people via sensors and other devices. Devices help to bridge the communication gap between the virtual world and the physical world making learning a simple thing. Thus students can learn wherever they are without going to school making learning fun, cheap and reliable.

The previous developments towards fully fledged E-learning involving science subjects are presented in the next section.

\section{Developments in Towards E-Learning}

The concept of e-learning is being sung louder and louder each day. This is because the development of learning infrastructure cannot catch up with demand. As a way towards achieving the e-learning related to science subjects, the issue of simulations has had more pronounced development.

Simulation is the imitation of the operation of a real-world process or system over time. The act of simulating something first requires that a model be developed to represent the key characteristics or behavioral functions of the selected physical or abstract system/process. The model represents the system itself, whereas the simulation represents the operation of the system over time.

The following systems are used in Chemistry and Physics simulation worlds.

\subsection{PhET interactive Simulations}

PhET, based at the University of Colorado at Boulder, offers a wide range of interactive simulations in all sciences, with over three dozen chemistry-based simulations. The simulations are extensively tested and evaluated. PhET was founded in 2002 by Nobel Laureate Carl Wieman and the PhET Interactive Simulations project at the University of Colorado Boulder creates free interactive math and science simulations. PhET simulations are based on extensive education research and engages students through an intuitive, game-like environment where students learn through exploration and discovery [5]

\subsection{MERLOT Simulation Collection}

The Multimedia Educational Resource for Learning and Online Teaching (MERLOT) at the California State University has collected descriptions and links to a huge number of simulations. They include peer review ratings and comments, and information on their appropriateness for various levels [6]

\subsection{EveryCircuit}

EveryCircuit allows people to build and simulate circuits using their phones or tablets. People can animate and understand how their circuits work, check their homework and test their designs. Best of all, people can also join and interact with EveryCircuit's large online community of fellow circuit enthusiasts [7].

By looking at the above developments, it is clear that there are efforts to bring the laboratory into the computer. Although the natural feel of equipment is important, it is also equally important for those who cannot have access to the equipment to appreciate the operation through virtual laboratories. The next section is a detailed presentation of the development of the intelligent learning system.

\section{Development of the Interactive Learning System}

The interactive learning system was developed using a modularised approach. The system is basically a software product which is used to produce a virtual science laboratory. Tutorials are uploaded and experimental steps given for the student to follow. The visual experimental simulation has been developed to give the user a feel of the processes involved in the experiment. This section is a presentation of the system development. 


\subsection{Interactive System Packages}

The software architecture of the final application is shown in Fig. 1 and each package is a collection of classes with similar functions.

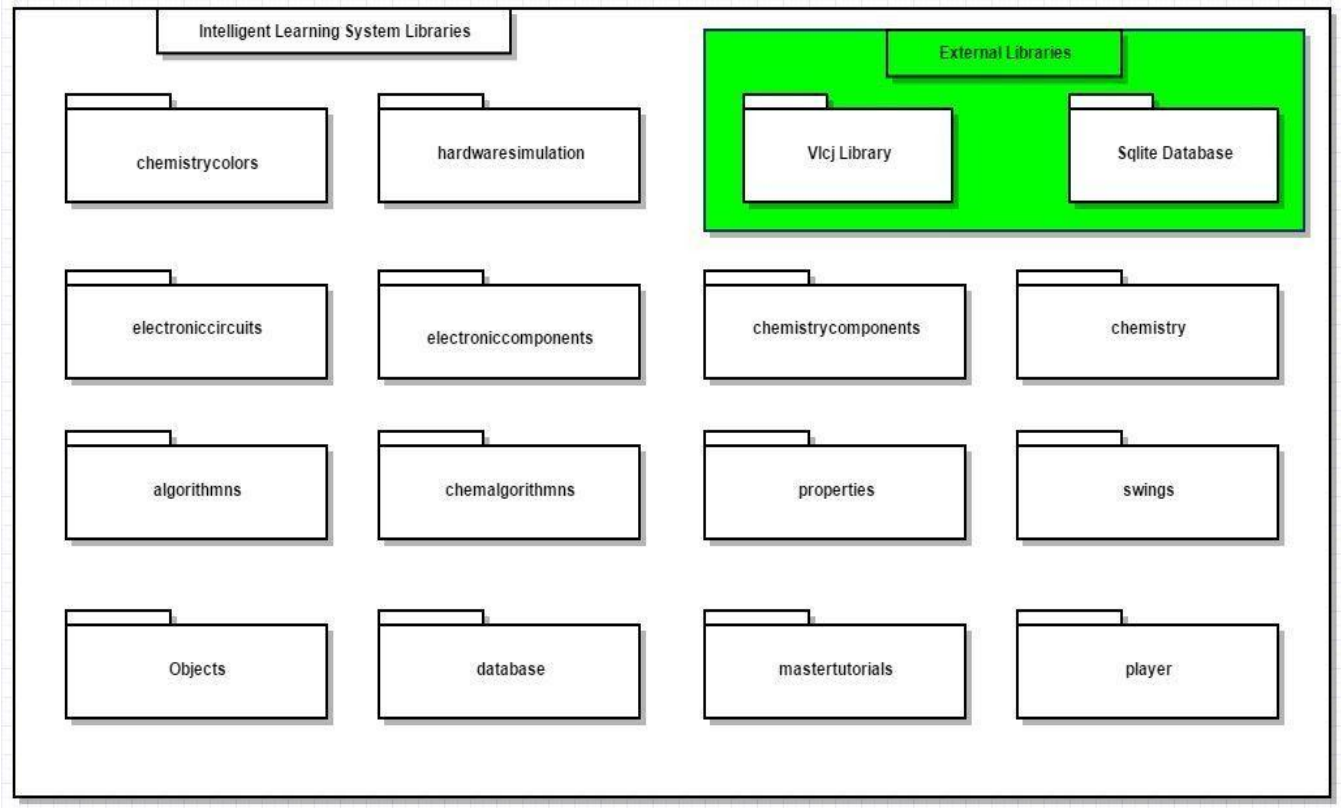

Fig. 1. The software system architecture and packages

Each package within the Intelligent Learning system groups all the classes with similar functions to achieve their aims goals.

\subsection{Software design and implementation}

The design and development of the intelligent learning system software is presented in this section. The preliminary results of each objective, components of the system and the overall architecture of the system are presented here. Use cases, and Unified Modelling Language (UML) sequence diagrams have been included to help the reader to fully understand how each package was designed.

Java programming language was chosen for the development of the main application due to its features such as cross platform independence, robustness and that it is Object Oriented.

\subsection{Design of the Video Player}

The video player was developed using Java as the programming language so that the application will be compatible with various operating system. However, the core of the video player is made up of library.

The VLCJ project is an Open Source project that provides Java bindings and an application framework for the excellent VLC media player from VideoLAN. The bindings can be used to build media player client and server software using Java to include everything from simply playing local media files to a full-blown video-on-demand streaming server. VLCJ is being used in diverse applications, helping to provide video capabilities to software in use on oceanographic research vessels and bespoke IPTV and home cinema solutions [8].

In order to speed up the video player design and development process it is wiser to have a rough sketch of the graphical user interface of the video player with all the necessary components such as buttons. Figure 2 shows the proposed video player layout with all the functions of each button and frames. The video player has a control panel (with buttons) in and a window to display the playing video. 


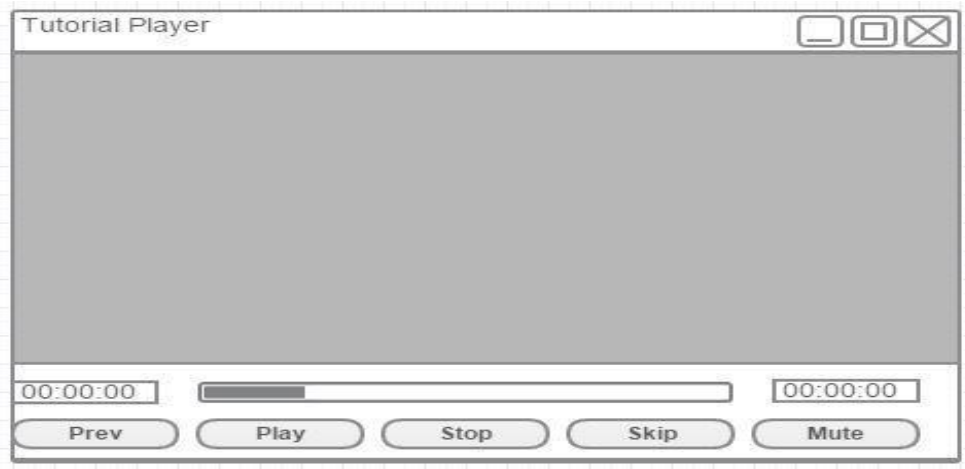

Fig. 2. The proposed video player.

\section{Design of Chemistry and Physics Simulators and Results}

The design of physics and chemistry simulator needs one to fully understand how each component works or how each apparatus is used. Moreover one should fully understand the properties of electronic components and if it is the chemistry side the user should fully understand the reaction properties that happen during a chemical reaction.

With all these in mind the best approach in the design of Physics and Chemistry simulator can be best designed in small classes. Each class explains the properties of apparatus or electronic component that will be used for simulations. Polymorphism was used so that all the classes can have the same blue print (structure) but different methods and properties. However, since the physics and chemistry simulators work the same way with the only difference being that the physics simulator will simulate circuits and chemistry simulator will simulate chemical reactions It was develop chemistry simulator then use the same principle in the design and development of physics simulator.

The development of the chemistry simulator is explained and the same concepts that have been used in the development of chemistry simulator have been used to develop a physics simulator. However, all the results for physics and chemistry simulators have been included as a way of supporting the design objectives.

The designed Chemistry Simulator is shown in Fig. 3.

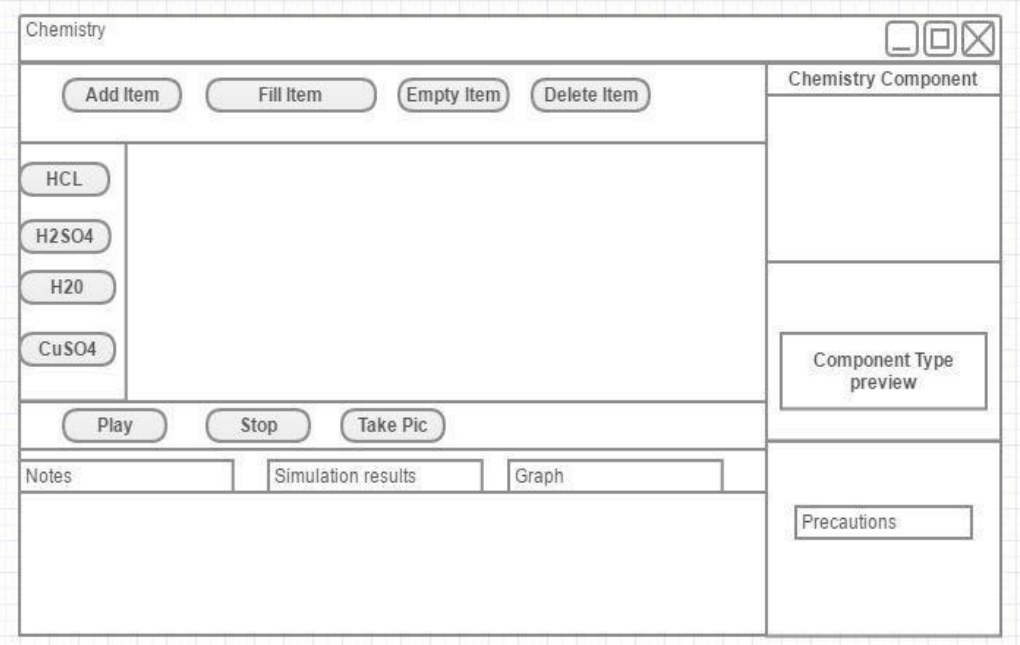

Fig. 3. The proposed Physics Simulator 


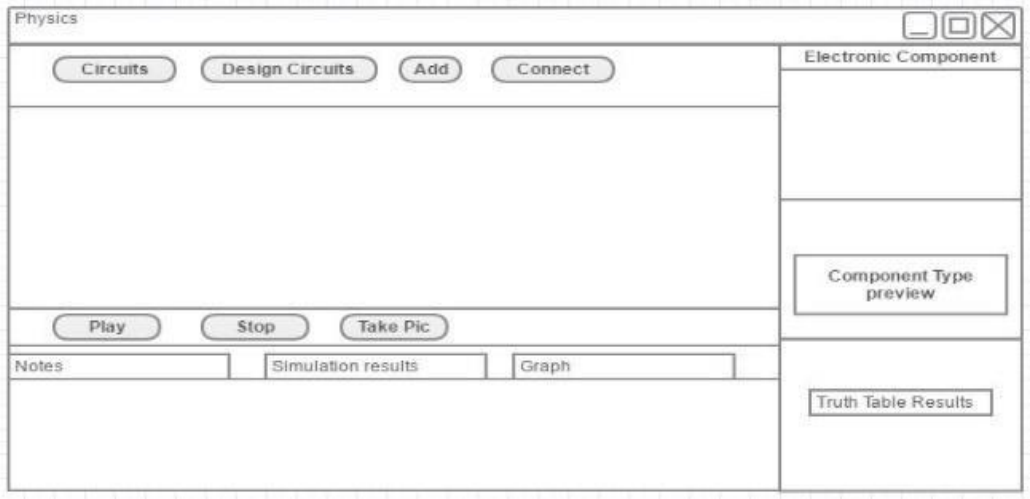

Fig. 4. The designed oscilloscope simulator

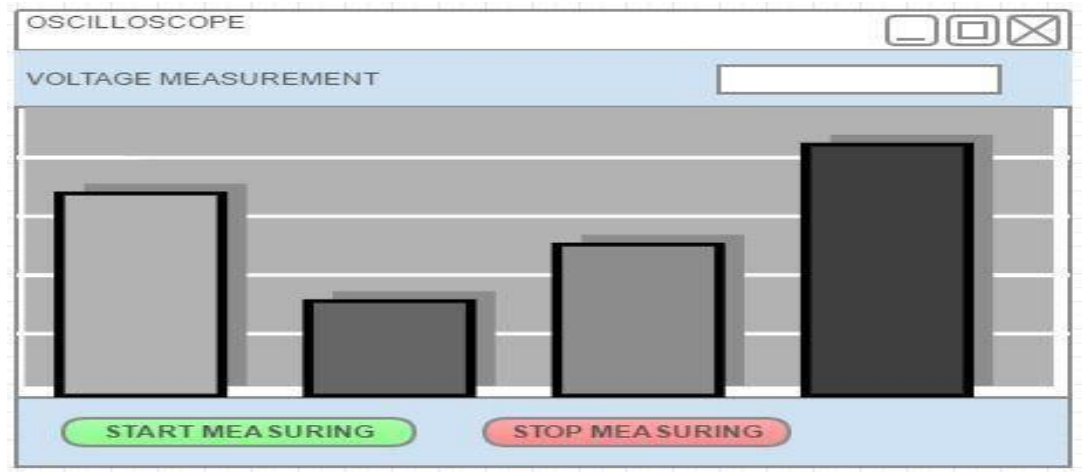

Fig. 5. Designed Physic simulator

Figs. 6 and 7 show the designed chemistry and physics simulators respectively. The simulators were designed and tested for simple functionality. The physics simulator uses simple logic circuits to design simple logical circuits. The components available for use are shown in Fig. 6.

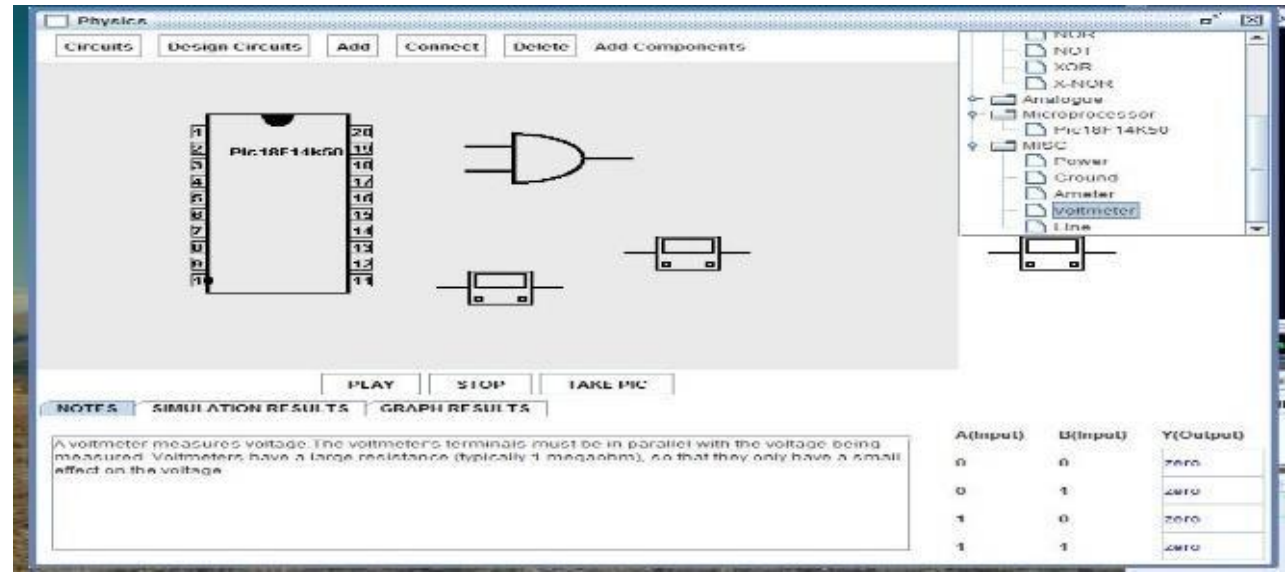

Fig. 6. The physics simulator interface 
The environment also gives the student a platform to ask questions. The tutorial has been designed with frequently asked questions with the objective to cover as many questions as possible so that the student can get a response from the system. An example is shown below.

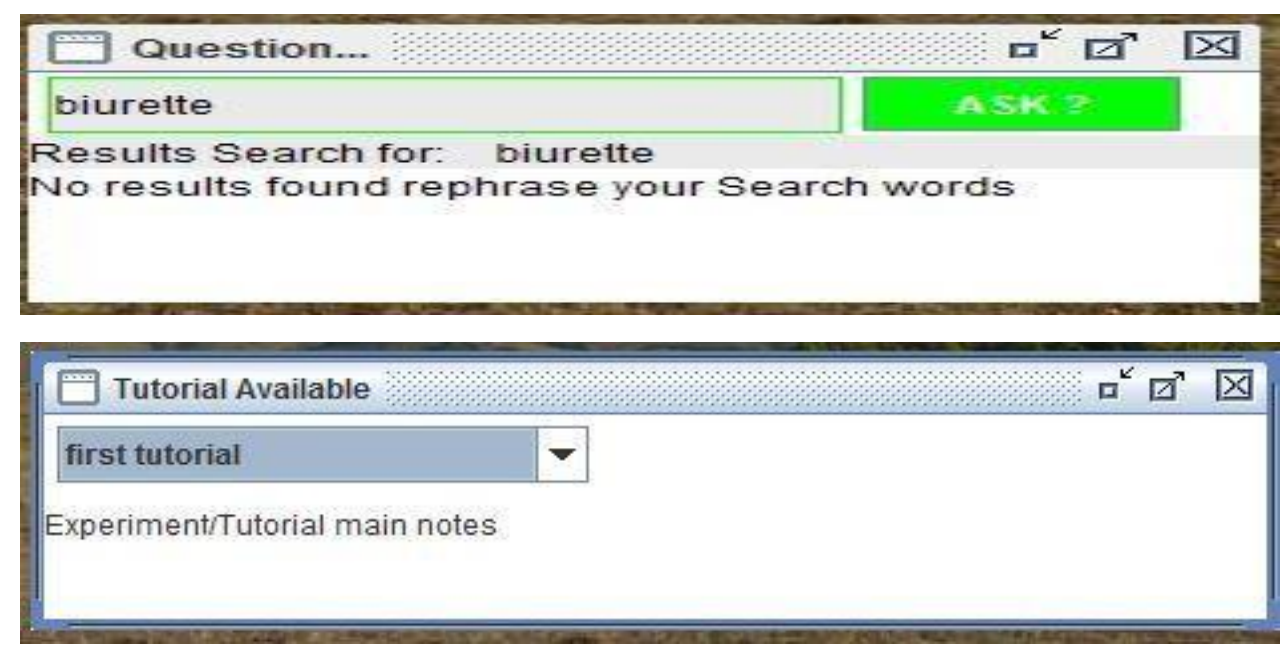

Fig. 7. The tutorial questions interface

Figs 8 to 12 show the designed tutorial uploader application starting with chemistry tutorial page one, followed by chemistry tutorial page two, chemistry tutorial page three and last physics tutorial page three. Figure 8 shows the home page for selecting the simulations to run. This gives the options to run either a physics or a chemistry simulation.

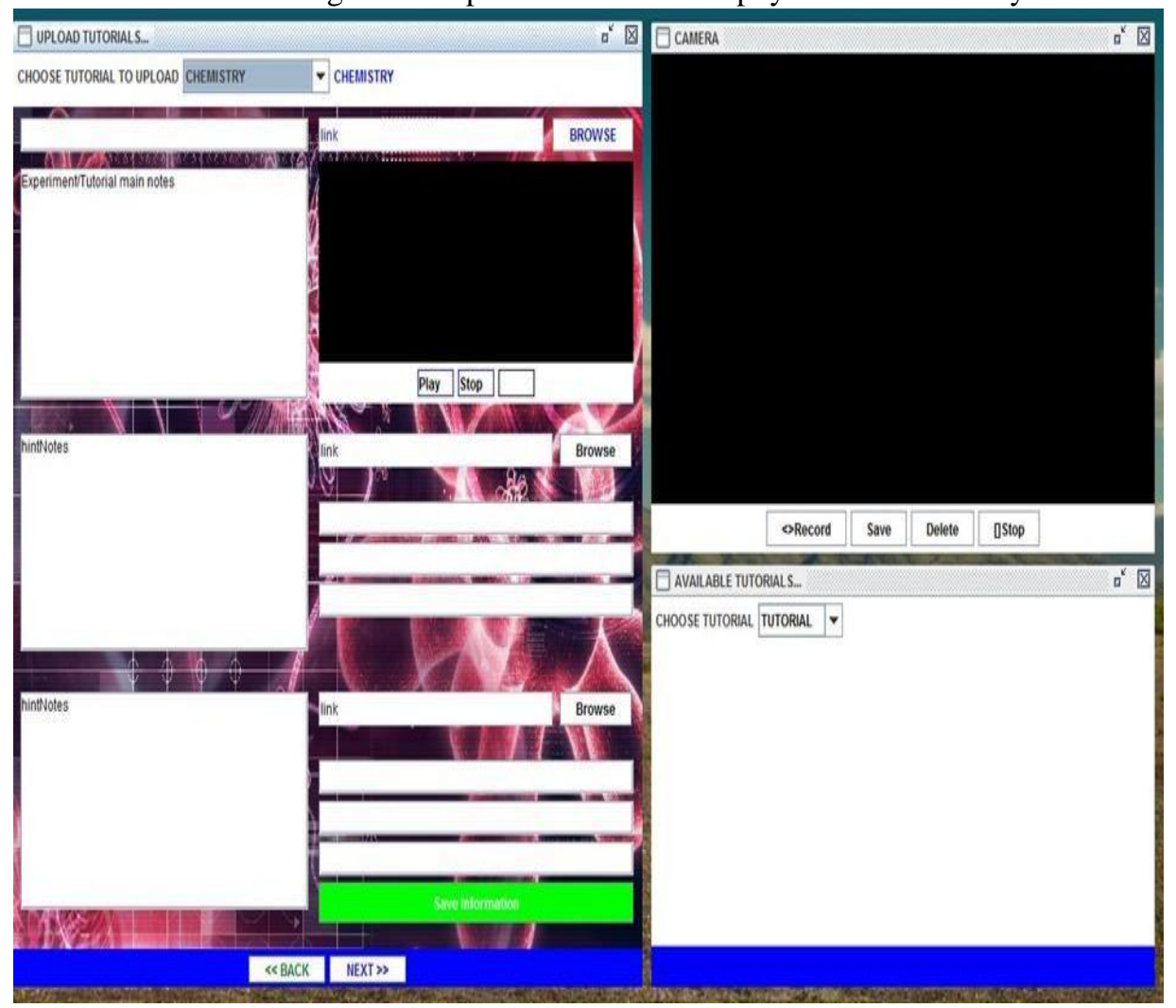

Fig. 8. Tutorial uploader initial page

If a chemistry tutorial is chosen, the window shown in Figure 9 is displayed for use. 


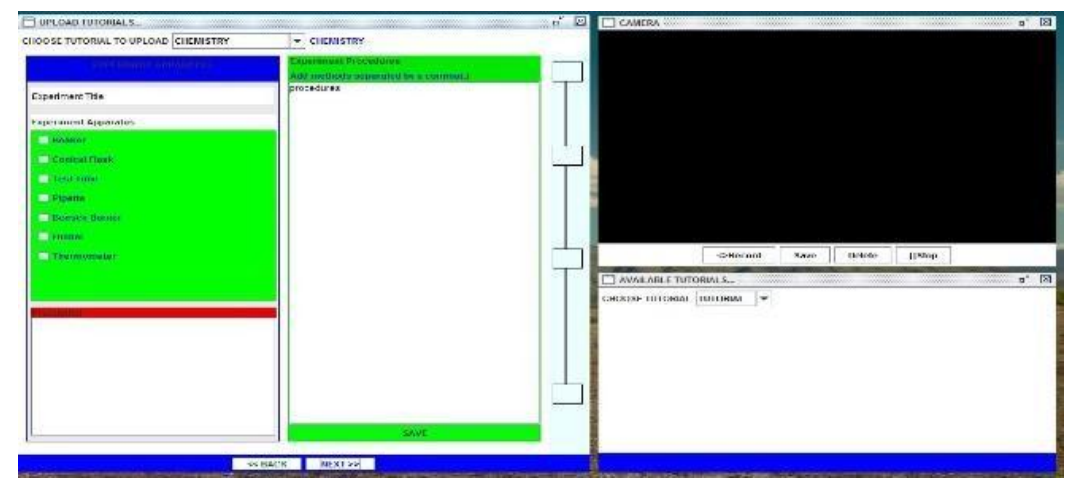

Fig. 9. Tutorial uploader chemistry second page

Following the choice, the interface on Fig. 10 allows the user to choose the chemicals to use in the titration example simulation given.

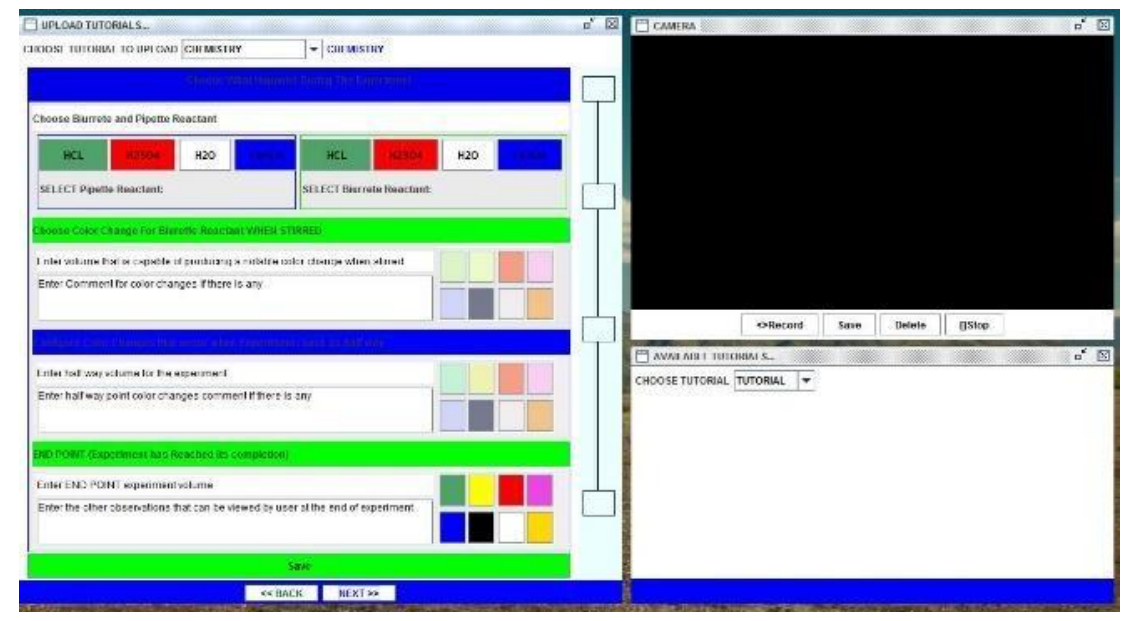

Fig. 10. Tutorial uploader chemistry third page

Figure 11 shows the equipment available for the chemistry simulation. These include the burette, the flasks and the test tubes as well as the chemicals.

Once the simulation is started, a timer runs to allow the measurement of the chemical quantities. The expected colour changes are also observed as the titration runs. These quantities and colour changes depends on the design given by the tutor.

The simulation environment gives the student a feel of the process without physically interacting with the physical equipment. This eliminates the limits imposed on disadvantaged students who cannot afford the equipment due to financial constraints.

Fig. 12 shows the interface for loading the physics tutorial and simulation. The same logic used in designing the chemistry simulation is also used to implement the simulation. It gives the same benefits of bringing the lab closer to the student. 


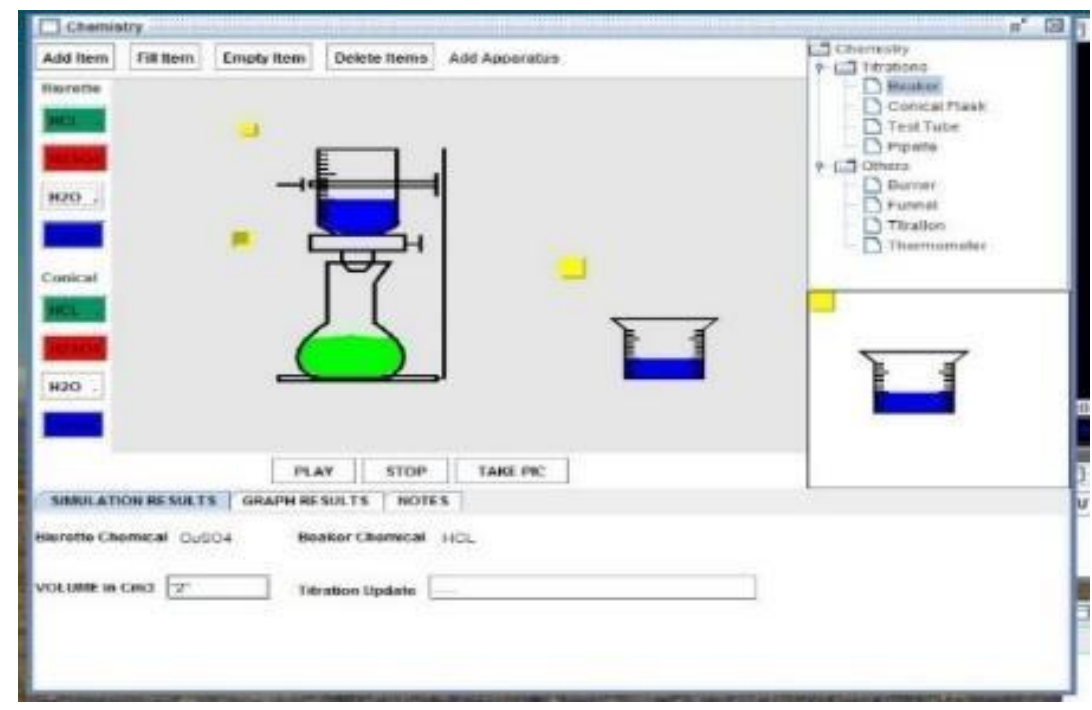

Fig. 11. Designed Chemistry Simulator

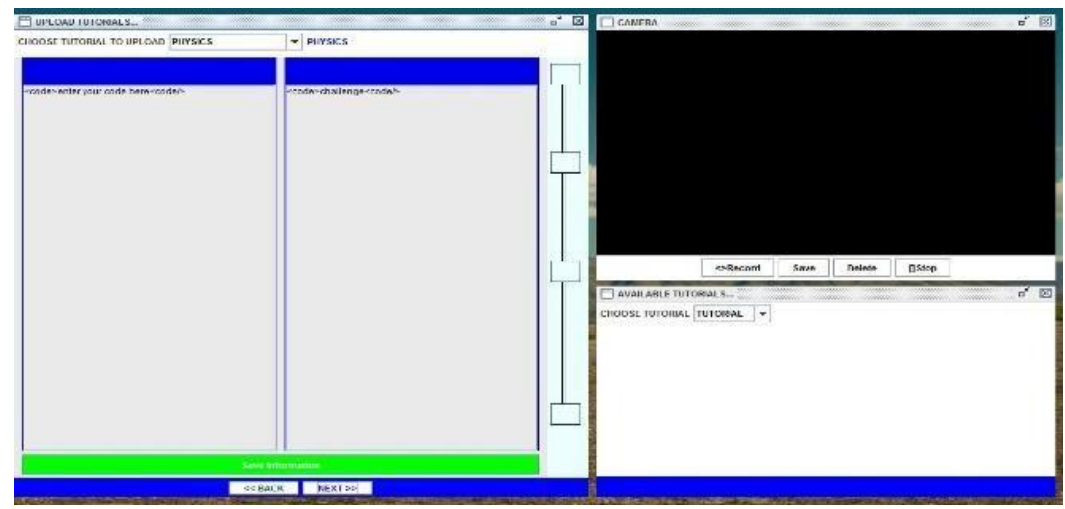

Fig. 12. Tutorial uploader physics page

\section{Conclusions.}

The design and development of the interactive intelligent system for E-learning, focusing on science subjects has been presented. The developed interfaces have been shown and it is evident from the results that the system is feasible. The design gives a virtual lab environment which gives students good exposure to the real laboratory setting. Such designs can be developed further to cater for more experiments and at the end give birth to a full-fledged virtual lab, the first of its kind in Zimbabwe.

\section{References}

[1] Freeman, S. et al. "Active learning increases student performance in science, engineering, and mathematics." Proceedings of the National Academy of Scientists, 111(23), pp. 8410-841 (2014)

[2] Associates, Edutech, "Internet of Learning-Things," Associates, Edutech, (2013)

[3] A. Toffler, Future Shock, Random House Publishing Group, (1970)

[4] M. Lloyd, "The High-Stakes Strategy," in http://bit.ly/19CUBju, Edutech, (2012)

[5] C. University, "http://phet.colorado.edu/," Colorado University, (2016). [Online]. Available: http://phet.colorado.edu/. [Accessed 03 April 2016]

[6] https://www.merlot.org, "https://www.merlot.org/merlot/materials.htm?," (2016). [Online]. Available:

[7] https://www.merlot.org/merlot/materials.htm?. [Accessed 03 April 2016].

[8] http://everycircuit.com, "http://everycircuit.com/," (2015). [Online]. Available: http://everycircuit.com/ . [Accessed 03 April 2015]. 